\title{
I Semana Internacional de la Provincia de Barcelona
}

\author{
por \\ M. BAENA DEL ALCAZAR
}

Durante los dias 23 al 27 del pasado mes de noviembre tuvo lugar en Barcelona la I Semana Internacional de la Provincia, organizada por el Instituto de Ciencias Sociales de la Diputación provincial. Con ello la Corporación catalana continúa una línea, ya iniciada anteriormente, de estudio y difusión de temas de interés para científicos de diversos países.

Los actos de la Semana se inauguraron el martes día 23 en el Palacio de la Diputación, haciendo uso de la palabra el Presidente de la Corporación, y scguidamente el ilustrísimo señor Director general de Administración Lucal. Esa misma tarde tuvo lugar el comienzo de las sesiones de trabajo, versando éste sobre la discusión de la Ponencia «Dimensión histórica de la Provincia», a cargo del profesor Jacques Godechot. En ella intervinieron, además de los españoles, destacados especialistas franceses e italianos, poniéndose de manifiesto por estos últimos los nexos históricos que ligan a Cataluña con algunas regiones italianas y especialmente con la isla de Cerdeña.

El día 24 se dedicó al estudio de la Ponencia referente a la Provincia y los medios de información, en la que se puso de relieve la importancia de la prensa en la Provincia, tema éste referente a la prensa en el que ya se había trabajado anteriormente en otros Congresos organizados por el Instituto de Ciencias Sociales de la Diputación.

Sin duda, uno de los temas de mayor interés a discutir era el referente a la organización y las funciones de la Provincia, que ocupó, respectivamente, la mañana y la tarde del día 25. Las Ponencias fueron expuestas por los profesores García de Enterría y Laubadère, y Entre- 
na Cuesta y Silvestri, habiendo ocupado este último la presidencia por la ausencia inesperada del profesor Miele. Merecen destacarse las intervenciones de los profesores Alvarez Gendín, Ortiz Díaz y Montoro Puerto entre los españoles, que en sus comunicaciones plantearon cuestiones de gran interés. Entre los profesores extranjeros hay que mencionar de un modo especial las comunicaciones del profesor Silvestri, del Abogado de la Corte dei Conti italiana, Onorato Sepe, y del profesor Orianne.

Las restantes Ponencias versaron sobre los aspectos políticos, sociológicos y económicos de la Provincia, siendo de destacar las comunicaciones del profesor Gessa y del profesor Quermonne entre los extranjeros, y las de Aguirre y Iuan Díez Nicolás entre los españoles, no debiendo omitirse la mención de don Jorge Xifra Heras, Director del Instituto de Ciencias Sociales y protagonista directo de la organización de la Semana.

Los actos se clausuraron con asistencia del excelentísimo señor Subsecretario de Gobernación y primeras autoridades barcelonesas el día 27 de noviembre, siendo toda la Semana una muestra excelente, a más de las tradicionales hospitalidad y cortesía barcelonesas, de la preocupación mostrada por la Diputación provincial en orden al planteamiento y solución de cuestiones de gran actualidad científica y cultural. 